\title{
Modes of Resistance to Benzylpenicillin and Ampicillin in Twelve Klebsiella Strains
}

\author{
BY J. M. T. HAMILTON-MILLER \\ Department of Bacteriology, Guy's Hospital Medical School, London, S.E. 1
}

(Received 24 March 1965)

\begin{abstract}
SUMMARY
Tube sensitivity tests show that, of twelve penicillins, ampicillin, benzylpenicillin and 6-aminopenicillanic acid were the most active when tested against medium-sized inocula $\left(10^{6}\right.$ organisms $)$ of twelve strains of penicillinase-producing Klebsiella (11 Klebsiella aerogenes and $1 \mathrm{~K}$.ozaenae), which had been isolated from clinical material and were resistant to both ampicillin and tetracycline. An inoculum size effect was consistently noted when ampicillin and benzylpenicillin were tested against different inocula; the effect was significantly greater with ampicillin. The following parameters were measured for the strains, using both benzylpenicillin and ampicillin: magnitude of the inoculum size effect; inherent sensitivity (sensitivity of a small inoculum); rate of penicillin destruction; ability of penicillins to pass bacterial permeability barriers. From considerations of the relationships between these values, it has been concluded that penicillinase is primarily responsible for the observed resistance of only two of the twelve strains; although penicillinase and the lack of ability of penicillins to obtain free access into the bacterial cells add to the over-all penicillin resistance of the other ten strains, the primary reason for their penicillin resistance is neither their possession of penicillinase nor their permeability barrier: such resistance presumably reflects an innate lack of sensitivity of the cell wall synthesizing complex to inhibition by penicillins.
\end{abstract}

\section{INTRODUCTION}

Ampicillin, a 'broad spectrum' semisynthetic penicillin, has been shown to be active (Rolinson \& Stevens, 1961) against several species of Gram-negative bacteria as well as against Gram-positive organisms; however, it has not proved to be effective, either in clinical or in laboratory studies, against some species of Gramnegative bacteria, notably Klebsiella aerogenes and certain strains of Proteus and Pseudomonas (Trafford et al. 1962; Barber \& Waterworth, 1964). Such organisms have become relatively more important as hospital pathogens (Anderson et al. 1964) since the introduction of the 'penicillinase-stable' penicillins, methicillin and cloxacillin, which has temporarily checked the penicillinase-producing Staphylococcus aureus. It is of considerable interest, from a fundamental as well as from a clinical viewpoint, to determine why $K$. aerogenes is insusceptible to ampicillin therapy. In some cases it has been shown that the resistance of certain strains of Gram-negative bacteria is due, solely or in part, to the possession by these organisms of penicillinase (Percival, Brumfitt \& de Louvois, 1963; Sutherland, 1964); these experiments were performed using relatively few laboratory strains. Now that it has been shown that some penicillinase-producing organisms destroy ampicillin only very slowly (Ayliffe, 
1963; Hamilton-Miller, 1963 b; Percival et al. 1963; Sabath \& Finland, 1963; Smith, 1963; Smith \& Hamilton-Miller, 1963), the mere possession of this enzyme by a particular bacterial strain can no longer be invoked, as it has been in the past, to explain fully the resistance to ampicillin therapy of that strain.

The genus Klebsiella has so far proved intransigent to ampicillin therapy (Trafford et al. 1962; Anderson et al. 1964), and this paper is concerned with some facets of this resistance in twelve strains, with particular reference to their in vitro lack of sensitivity to ampicillin and benzylpenicillin. A brief report of part of the work described here has been made (Hamilton-Miller, Smith \& Knox, 1964).

\section{METHODS}

Bacterial strains: all the organisms used in these studies have been isolated from clinical material obtained in this hospital. Klebsiella aerogenes strains 1, 43, 366, 370, $373,402,407,414,415$ and 418 were isolated, during 1961 and early 1962, in a clinical trial of ampicillin (Trafford et al. 1962); K. aerogenes 83 and $K$. ozaenae 61 were both isolated in 1964 from chest infections. The strains were identified and classified by means of their biochemical reactions as interpreted by Cowan, Steel, Shaw \& Duguid (1960). Penicillinase activity was detected by means of a membrane method, and acylase activity excluded by an extraction technique; in most cases the hydrolysis product of benzylpenicillin was identified as benzylpenicilloic acid by chromatography, all as previously described (Hamilton-Miller, 1963a). Cultures were maintained upon agar slopes and stored at $4^{\circ}$; they were subcultured every 6 months.

Tube sensitivity tests: serial doubling dilutions, in a final volume of $1 \mathrm{ml}$., of the various penicillins were made in infusion broth (Southern Group Laboratories, Hither Green, London, S.E. 13); tubes were inoculated with one drop (0.02 ml.) of a suitable dilution of a $6 \mathrm{hr}\left(37^{\circ}\right)$ culture of the requisite coliform organism (such cultures usually contained about $5 \times 10^{7}$ bacteria/ml. before dilution). Tubes were incubated overnight $(16 \mathrm{hr})$ at $37^{\circ}$ and then read: the lowest concentration of penicillin which completely prevented growth was taken as the minimum inhibitory concentration. Inoculum sizes were counted by making serial decimal dilutions of the inoculum stock suspension, dropping $0.02 \mathrm{ml}$. on to blood agar, and counting the colonies after overnight incubation at $37^{\circ}$. The results of the tube sensitivity tests were interpreted as follows: the minimum inhibitory concentrations using small inocula were taken as measures of the 'intrinsic' resistance of each strain, while the ratio of the minimum inhibitory concentration using a large inoculum to that using a small inoculum was taken as a measure of the resistance due to penicillinase (the validity of this assumption is discussed in a later section).

Penicillins. Na benzylpenicillin (Crystapen) was obtained from Glaxo Ltd, Greenford, Middlesex; phenoxymethylpenicillin (penicillin V), K phenoxyethylpenicillin (Broxil, phenethicillin), $\mathbf{K}$ phenoxypropylpenicillin (Brocillin, propicillin), Na 2,6-dimethoxyphenylpenicillin (Celbenin, methicillin), $\alpha$-aminobenzylpenicillin (Penbritin, ampicillin), Na 5-methyl-3-phenyl-4-isoxazolylpenicillin (oxacillin), Na 5-methyl-3-p-chlorphenyl-4-isoxazolylpenicillin (BRL 1577), $\mathrm{Na}$ 5-methyl-3-ochlorphenyl-4-isoxazolylpenicillin (Orbenin, cloxacillin), and 6-aminopenicillanic acid were gifts of Beecham Research Laboratories Limited, Brockham Park, Surrey; phenoxybenzylpenicillin (Penspek, phenbenicillin) was a gift from The Distillers 
Company (Biochemicals) Ltd, Speke, Liverpool; $\mathrm{Na}_{2}$ 3-carboxy-2-quinoxalinyl penicillin (quinacillin) was a gift from Boots Pure Drug Company, Nottingham.

Properties of penicillinases: these were investigated as previously described (Hamilton-Miller, 1963a), using the hydroxylamine assay. Cultures were incubated statically in infusion broth at $37^{\circ}$ for $16 \mathrm{hr}$, harvested by centrifugation, washed and resuspended at a suitable concentration in 25 mM sodium phosphate buffer, $\mathrm{pH} \mathbf{7 \cdot 4}$; whole-cell and supernatant fractions of broth cultures were assayed for penicillinase activity (see Results). Disruption of bacterial suspensions was brought about, when desired, by treatment for $5 \mathrm{~min}$. in the M.S.E. $60 \mathrm{~W}$. ultrasonic disintegrator, using a probe of end diameter $1.9 \mathrm{~cm}$., the suspension being cooled in an ice-water bath; preparations were then centrifuged at $30,000 \mathrm{~g}$ for $35 \mathrm{~min}$. at $4^{\circ}$.

Concept and definition of 'permeability factor': as penicillinase activity was strictly intracellular in the strains studied here (see Results) it is valid to assume that any increase in enzymic activity which follows disruption of cells is due to removal of substrate accessibility barriers which, in intact cells, limit the rate of entry of substrate into the interior of the cell. The value of this increase can be taken as a quantitative measure of the ease with which various substrates are able to penetrate the cell membrane. In this paper, such values are expressed as 'permeability factors', which were determined in the following way: a suitable suspension of washed cells was prepared, a portion disrupted and both intact and disrupted preparations assayed against the required substrate. 'The permeability factor is defined as the ratio of the rate of hydrolysis by the disrupted sample to the rate of hydrolysis by the intact preparation.

\section{RESULTS}

Location of penicillinase. Overnight broth cultures of all the strains were centrifuged, and the resuspended pellets assayed in parallel with the supernatant fractions. In no case was any penicillinase activity found in the extracellular fluid. Cell debris obtained by centrifugation of ultrasonically disintegrated suspensions (see 'Methods') was also devoid of penicillinase activity. In whole untreated cultures, therefore, it appears that penicillinase is a wholly intracellular enzyme, probably confined to the 'soluble cytoplasm' of the bacteria (Hamilton-Miller, 1963a). Solubilization of penicillinase activity was caused only by methods that completely destroyed the architecture of the bacterial cell (e.g. ultrasonic treatment, extrusion, freezing and thawing-see Hamilton-Miller, 1964). Methods which, while partially or completely destroying the permeability barriers which render penicillinase cryptic, nevertheless leave the cells viable and microscopically intact [namely culture in subinhibitory concentrations of various penicillins (Smith, 1963; Smith \& HamiltonMiller, 1963; Hamilton-Miller, 1963a), or treatment with mM EDTA (HamiltonMiller, 1964)], did not result in release of penicillinase into the extracellular fluid.

Properties of penicillinases. The following properties and characteristics of the penicillinases from each of the twelve Klebsiella strains were studied: specificity patterns, using twelve substrates; $\mathrm{pH}$-activity characteristics; permeability of bacteria to various penicillins; apparent energies of activation; susceptibility to inhibition by substrate analogues; inducibility. These properties were similar in all respects to those described in previous studies involving only some of the strains (Hamilton-Miller, 1963 $a$, 1964; Smith \& Hamilton-Miller, 1963; Hamilton-Miller \& 
Smith, 1964). Table 1 shows absolute activities and permeability factors for the twelve strains using benzylpenicillin and ampicillin as substrates. The properties which are of particular relevance to the present study are as follows: ampicillin was hydrolysed more rapidly than was benzylpenicillin by both cell-free and whole-cell preparations from all the strains; enzymic activity was maximal between $\mathrm{pH}$ values 6 and 8 ; the affinity of the penicillinases for benzylpenicillin was uniformly high $\left(K_{m}<50 \mu \mathrm{g} . / \mathrm{ml}.\right)$; the enzyme was in no case inducible.

\section{Table 1. Absolute activity and permeability factors for twelve Klebsiella strains against benzylpenicillin and ampicillin}

\begin{tabular}{|c|c|c|c|c|c|}
\hline & & \multicolumn{2}{|c|}{ Benzylpenicillin } & \multicolumn{2}{|c|}{ Ampicillin } \\
\hline & & $\begin{array}{l}\text { Absolute } \\
\text { activity }\end{array}$ & $\mathbf{P}$ & $\begin{array}{l}\text { Absolute } \\
\text { activity }\end{array}$ & $\mathbf{P}$ \\
\hline K. aerogenes & 1 & 10 & 6 & 19 & $\gamma$ \\
\hline & 43 & $10 \cdot 5$ & 11 & $21 \cdot 8$ & $12 \cdot 5$ \\
\hline & $\mathbf{8 3}$ & $1 \cdot 7$ & 1.5 & $2 \cdot 5$ & 1.5 \\
\hline & 366 & 3180 & 11 & 6300 & 14 \\
\hline & 370 & 22 & 8 & 37 & 8 \\
\hline & $\mathbf{3 7 3}$ & 1360 & 9 & 2660 & 5 \\
\hline & 402 & $7 \cdot 6$ & $\mathbf{3}$ & $15 \cdot 8$ & 2 \\
\hline & 407 & $5 \cdot 4$ & 3 & $8 \cdot 7$ & 2 \\
\hline & 414 & $3 \cdot 8$ & 2 & 6 & 2 \\
\hline & 415 & $10 \cdot 3$ & 4 & 28 & 3 \\
\hline & 4,18 & $20 \cdot 6$ & 4 & 35 & 4 \\
\hline K. ozaenae & 61 & $22 \cdot 3$ & $2 \cdot 5$ & 40 & 3 \\
\hline
\end{tabular}

Antibacterial activity of different penicillins. As the minimum inhibitory concentration of a penicillin acting against a penicillinase-producing organism is, under certain circumstances, dependent upon the size of the inoculum that is used (Luria, 1946; Knox \& Smith, 1961; Hamilton-Miller et al. 1964), standardized conditions were employed for this series of experiments. An initial inoculum of about $10^{6}$ organisms/tube was used. Eleven strains of Klebsiella were tested in this way, and minimum inhibitory concentrations were determined for eleven penicillins and 6aminopenicillanic acid; results are shown in Table 2. The mean values of the minimum inhibitory concentrations of each compound for all the strains were then calculated, in an attempt to obtain a coherent idea of the relative antibacterial activities of this series of drugs; these figures are also shown in Table 2. It can be seen that benzylpenicillin, ampicillin and 6-aminopenicillanic acid are the most active compounds against Klebsiella strains, using this inoculum size. However, with the possible exception of Klebsiella ozaenae 61, the minimum inhibitory concentrations observed here are all very much greater than the concentrations that can be attained in the body during therapy.

Inoculum size effects. Some strains of Klebsiella aerogenes were found to show an inoculum size effect when tested against ampicillin or benzylpenicillin (HamiltonMiller et al. 1964). The magnitude of this effect was measured for each strain using ampicillin and benzylpenicillin, by determining the ratio of the minimum inhibitory 
concentration with a large inoculum (about $10^{7}$ organisms/tube) to that with a small inoculum (about 10 organisms/tube). Preliminary investigations showed that varying the size of the inoculum between 100 and 10 organisms per tube did not alter the minimum inhibitory concentration; hence, for all practical purposes, an inoculum size of $\mathbf{1 0 0}$ organisms is equivalent to one of 10. Both are physiologically 'small' inocula in the sense that the minimum inhibitory concentrations obtained by their use reflect the inherent sensitivity of a strain. Table 3 shows the results of these experiments: the magnitude of the inoculum size effects obtained using ampicillin was found to be significantly greater $(t=2.781$ with 18 degrees of freedom, $P<0.02)$ than that obtained using benzylpenicillin. $K$. aerogenes strains 366 and 373 have been omitted from this series, as their intrinsic resistance to ampicillin (minimum inhibitory concentration against small inocula $=12.5 \mathrm{mg} . / \mathrm{ml}$.) was so great that the full extent of the inoculum size effect could not be measured; it was also difficult to obtain a sufficiently concentrated solution of ampicillin in broth at the correct $\mathrm{pH}$ value with which to initiate the serial dilutions. The intrinsic resistance of these two strains to benzylpenicillin was also very great (minimum inhibitory concentration against small inocula $=1.5 \mathrm{mg} . / \mathrm{ml}$.).

Table 2. Minimum inhibitory concentrations ( $\mathrm{g} . / \mathrm{ml}$.) of twelve drugs for eleven Klebsiella strains

\begin{tabular}{|c|c|c|c|c|c|c|c|c|c|c|c|c|}
\hline \multicolumn{13}{|c|}{ Inoculum size was $10^{8}$ organisms/tube. } \\
\hline & 1 & 43 & 83 & 366 & 370 & 402 & 407 & 414 & 415 & 418 & & \\
\hline $\begin{array}{l}\text { Benzylpenicillin } \\
\text { Phenoxymethylpenicillin } \\
\text { Phenethicillin } \\
\text { Propicillin } \\
\text { Ampicillin } \\
\text { Phenbenicillin } \\
\text { 6-aminopenicillanic acid } \\
\text { Methicillin } \\
\text { Oxacillin } \\
\text { Cloxacillin } \\
\text { BRL 1577 } \\
\text { Quinacillin }\end{array}$ & $\begin{array}{r}1,000 \\
2,000 \\
4,000 \\
4,000 \\
1,500 \\
2,000 \\
500 \\
10,000 \\
2,000 \\
1,000 \\
4,000 \\
>8,000\end{array}$ & $\begin{array}{r}500 \\
1,000 \\
2,000 \\
2,000 \\
500 \\
500 \\
1,000 \\
4,000 \\
2,000 \\
1,000 \\
1,000 \\
>8,000\end{array}$ & $\begin{array}{r}31 \\
125 \\
1,000 \\
500 \\
31 \\
250 \\
62 \\
4,000 \\
1,000 \\
1,000 \\
1,000 \\
>\mathbf{4 , 0 0 0}\end{array}$ & $\begin{array}{r}2,500 \\
2,500 \\
10,000 \\
10,000 \\
2,500 \\
1,000 \\
2,500 \\
1,000 \\
800 \\
400 \\
1,000 \\
>\mathbf{4 , 0 0 0}\end{array}$ & $\begin{array}{r}125 \\
500 \\
2,000 \\
2,000 \\
250 \\
500 \\
250 \\
2,000 \\
1,000 \\
1,000 \\
2,000 \\
4,000\end{array}$ & $\begin{array}{r}100 \\
625 \\
2,500 \\
1,250 \\
75 \\
400 \\
200 \\
2,500 \\
625 \\
1,250 \\
1,250\end{array}$ & $\begin{array}{r}125 \\
900 \\
2,000 \\
2,000 \\
250 \\
\mathbf{5 0 0} \\
250 \\
4,000 \\
1,000 \\
1,000 \\
1,000 \\
>8,000\end{array}$ & $\begin{array}{r}250 \\
500 \\
2,000 \\
1,000 \\
1,000 \\
2,000 \\
250 \\
2,000 \\
500 \\
1,000 \\
1,000 \\
>8,000\end{array}$ & $\begin{array}{r}\mathbf{8 0} \\
400 \\
1,000 \\
1,000 \\
90 \\
\mathbf{3 0 0} \\
70 \\
2,000 \\
500 \\
1,000 \\
700\end{array}$ & $\begin{array}{r}220 \\
500 \\
2,000 \\
1,000 \\
200 \\
400 \\
70 \\
4,000 \\
1,000 \\
1,000 \\
>4,000\end{array}$ & $\begin{array}{r}16 \\
32 \\
125 \\
125 \\
16 \\
\mathbf{3 2} \\
64 \\
64 \\
64 \\
64 \\
64 \\
>4,000\end{array}$ & $\begin{array}{r}450 \\
825 \\
2,600 \\
2,260 \\
580 \\
715 \\
475 \\
3,240 \\
955 \\
885 \\
1,300 \\
>4,000\end{array}$ \\
\hline
\end{tabular}

On prima facie grounds it might be expected that, if resistance to benzylpenicillin and ampicillin is due solely to penicillinase activity, the more penicillinase activity a strain possesses, the greater should the resistance of that strain be. To test this hypothesis, the correlation was calculated between penicillinase activity against extent of penicillinase-type resistance displayed (as exemplified by the magnitude of the inoculum size effect). As can be seen from Table 4, rows $A$ and $B$, there is no significant correlation between the penicillinase activity of a strain and the degree of penicillinase-type resistance shown by it, either toward benzylpenicillin or ampicillin.

The minimum inhibitory concentrations determined using the small inoculum can be taken as a measure of the inherent resistance of each strain to the penicillin tested. Again, in all cases except Klebsiella aerogenes 83 and $K$. ozaenae 61 (which had been selected for study originally because they showed a zone of inhibition around a $15 \mu \mathrm{g}$. ampicillin disk on solid media), the concentration of any drug tested here required to inhibit the growth of a small inoculum was greater than the level of that drug that can be attained in vivo during therapy; i.e. the ten strains were inherently resistant to penicillins. However, it was found that a significant degree of correla- 
Table 3. Minimum inhibitory concentrations (m.i.c.) of benzylpenicillin and ampicillin ( $\mu \mathrm{g} . / \mathrm{ml}$.) for large (columns 2 and 5) and small (columns 2 and 6) inocula of ten Klebsiella strains

Ratio (columns 4 and 7 ) of $m$.i.c. for large inoculum to m.i.c. for small inoculum gives a measure of amount of resistance due to penicillinase; m.i.c. for small inoculum gives a measure of inherent susceptibility of each strain.

\begin{tabular}{|c|c|c|c|c|c|c|c|}
\hline & & & icill & & & peni & \\
\hline & & In & & & & & \\
\hline Bacterial $\mathbf{s}$ & rain & $10^{7}$ & 10 & Ratio & $10^{7}$ & 10 & Ratio \\
\hline K. aerogenes & 1 & 2,000 & 31 & 64 & 1,000 & 81 & 32 \\
\hline & 43 & 1,000 & 81 & 32 & 1,000 & 63 & 16 \\
\hline & 83 & 250 & 8 & 32 & 125 & 8 & 16 \\
\hline & 370 & 2,000 & 16 & 128 & 1,000 & 31 & 32 \\
\hline & 402 & 1,000 & 31 & 32 & 400 & 50 & 8 \\
\hline & 407 & 1,000 & 16 & 64 & 500 & 31 & 16 \\
\hline & 414 & 1,000 & 16 & 64 & 500 & 31 & 16 \\
\hline & 415 & 200 & 13 & 16 & 400 & 28 & 16 \\
\hline & 418 & 1,000 & 25 & 40 & 128 & 31 & 4 \\
\hline K. ozaenae & 61 & 250 & 4 & 64 & 250 & 4 & 64 \\
\hline Mean & & 一 & 一 & $53 \cdot 6$ & - & - & $22 \cdot 0$ \\
\hline S.D. & & - & - & $31 \cdot 6$ & - & - & $17 \cdot 2$ \\
\hline
\end{tabular}

Table 4. Results of tests of correlation between various pairs of parameters measured in these experiments

Rates of breakdown, and permeability factors, for benzylpenicillin and ampicillin taken from Table 1. Penicillinase type resistance taken from Table 3-ratio of minimum inhibitory concentrations obtained using large and small inocula; inherent resistance taken from Table 3-value of minimum inhibitory concentration using small inocula.

Correlation tested between $\quad t$ value $\begin{gathered}\text { Degrees of } \\ \text { freedom }\end{gathered} \quad$ Significance level

(A) Penicillinase-type resistance to benzylpenicillin vs. rate of breakdown of benzylpenicillin

(B) Penicillinase-type resistance to ampicillin vs. rate of breakdown of ampicillin

(C) Inherent resistance to benzylpenicillin $v s$. permeability factor to benzylpenicillin

(D) Inherent resistance to ampicillin $v s$. permeability factor to ampicillin

(E) Inherent resistance to ampicillin vs. $\quad \mathbf{8 . 5 5 5}$ inherent resistance to benzylpenicillin

$$
\text { 1.329 } 10 \quad P=0.22 \text { (not significant) }
$$

$0 \cdot 0129 \quad 8$

2.553 $10 \quad P=0.03$ (significant)

$10 P<0.001$ (highly significant)
$10 \quad P=0.11$

tion existed between the inherent resistance of these strains and the ease with which benzylpenicillin penetrated through the permeability barrier into the bacteria (Table 4, row C). Although in the case of ampicillin the correlation between these factors is not significant at the $5 \%$ level (Table 4, row D) it is worthy of note that the probability of the degree of correlation observed being due purely to chance is only 
$11 \%$. A further fact was observed, namely that the correlation between inherent resistance to ampicillin and inherent resistance to benzylpenicillin was highly significant (Table 4, row E).

\section{DISCUSSION}

It is interesting that both benzylpenicillin and 6-aminopenicillanic acid show activity approximately as great as ampicillin against resistant Klebsiella strains; against sensitive Gram-negative strains, ampicillin has been reported to be some ten times more active than benzylpenicillin (Rolinson \& Stevens, 1961). Further, there have been other reports (see Hamilton-Miller, 1963a) of 6-aminopenicillanic acid having greater antibacterial activity than either benzylpenicillin or ampicillin, against certain coliform organisms.

The assumption has been made (see 'Methods' section) that the inoculum size effect observed in these experiments is due to penicillinase. It seems probable that this is the correct explanation for the phenomenon, for the following reasons:

(1) All these organisms possess $\beta$-lactamase activity, which is effective at the penicillin concentrations and $\mathrm{pH}$ values used; ampicillin is more rapidly hydrolysed than benzylpenicillin by whole cell suspensions of these organisms, which correlates with the inoculum size effect being of significantly greater magnitude with ampicillin than with benzylpenicillin.

(2) The microbiological studies of Hamilton-Miller et al. (1964), which showed that the inoculum size effect in Klebsiella aerogenes can be drastically reduced by in vivo inhibition of penicillinase activity, rule out the possibility that non-specific penicillin destruction is responsible for the inoculum size effect, and directly implicate penicillinase in this role.

(3) Three of the strains used in these studies $(402,415$ and 418) have proved to have a homogeneous population structure in regard to their sensitivity both to benzylpenicillin and to ampicillin. (I am grateful to Mrs B. Heywood for performing these experiments).

While penicillinase has the capability of protecting large inocula against penicillins, the permeability barrier will be of particular importance when the sensitivity of individual bacterial cells is being considered: this inherent sensitivity has been shown to be low in most of the strains studied here, and bears no significant relationship to the extent of the permeability barrier to ampicillin. Hence it is very difficult to come to any other conclusion but that the inherent resistance of these strains to ampicillin is due to some other mechanism, such as an intrinsic lack of sensitivity on the part of the mucopeptide synthesizing enzyme complex to inhibition by this penicillin. The less permeable are the cells of a bacterial strain to benzylpenicillin, the more inherently resistant is that strain to this penicillin; it therefore seems possible that at least part of the reason for the high inherent resistance of most of the Klebsiella strains investigated here is the inability of benzylpenicillin to penetrate into the bacteria in adequate concentrations to cause bacteriostasis. The possession of a penicillinase which is capable of actively hydrolysing penicillins will serve to superimpose an additional resistance upon the inherent resistance. Moreover, the presence of a permeability barrier will actually enhance the effectiveness of the penicillinase (as pointed out by Percival et al. 1963): the rate of entry of the drug may be limited so that any which enters can be destroyed before it can cause damage in a 
cell which possesses, in conjunction with an accessibility barrier, a low level of penicillinase.

But as the inherent resistance of most of these strains is more than adequate to enable them to survive in those levels of ampicillin or benzylpenicillin that can be obtained during therapy, the role of the penicillinase, in conjunction with the permeability barrier, seems to be merely to increase the 'lack of sensitivity' of these strains.

The effect of the presence of penicillinase upon the susceptibility of bacterial strains to penicillins can be measured directly, as has been done in the experiments described in this paper, by observation of the magnitude of the inoculum size effect, or indirectly, by inhibition of the penicillinase activity in vitro in intact, viable cells, as was done by Hamilton-Miller et al. (1964) and by Sutherland \& Batchelor (1964), using methicillin to inhibit the enzyme. The results obtained from both avenues of exploration show that even in the absence of penicillinase-mediated penicillin destruction ten of these Klebsiella strains were inherently resistant to both benzylpenicillin and ampicillin. However, in view of the fact that in small inocula Klebsiella aerogenes 83 and $K$. ozaenae 61 were sensitive to ampicillin and benzylpenicillin in concentrations which can be attained in vivo during therapy, while in large inocula they were resistant to both drugs, it seems probable that these two strains owe their observed resistance to the fact that they possess penicillinase in conjunction with a permeability barrier; thus a parallel is shown with the results obtained by Percival et al. (1963) for Escherichia coli and Sutherland (1964) for Aerobacter aerogenes.

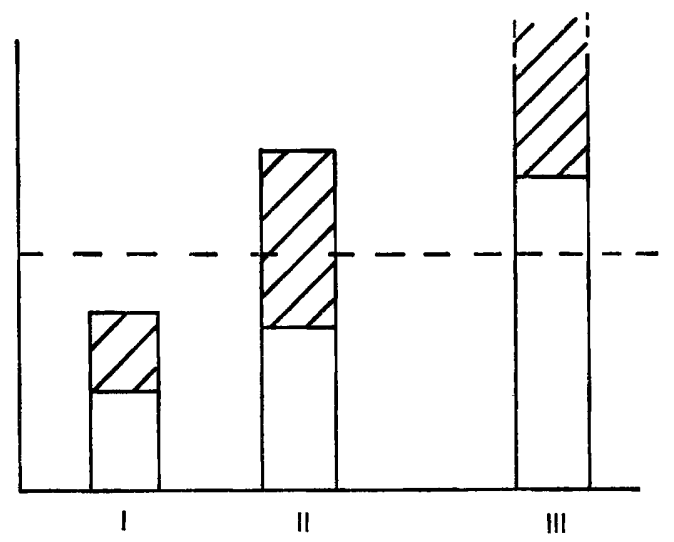

Fig. 1. The different classes of 'resistance' to a penicillin. Vertical axis represents minimum inhibitory concentration of drug; horizontal dotted line is the usually attained blood level of that drug. Height of bar represents degree of bacterial resistance: open part of bar is intrinsic resistance, hatched part is penicillinase type resistance. If height of bar exceeds blood level, strain is regarded as resistant. See text for characteristics of bacterial strains belonging to classes I, II and III.

Academically speaking, 'resistance' is impossible to define without picking some purely arbitrary, and therefore artificial, base-line (which is bound to be unsatisfactory). Clinically speaking, however, the base-line can be made the concentration of the drug which is usually attained in the serum of patients undergoing treatment; this definition will give satisfactory results. Consider the three situations which can 
obtain in the case of penicillinase-producing organisms, in respect of their resistance to penicillins (Fig. 1).

Class I contains sensitive organisms, with low intrinsic resistance, and low or negligible amounts of penicillinase; such strains will show a zone of inhibition around a 'low level' penicillin disc.

Class II strains have a low or moderate intrinsic resistance, and a moderate or high level of penicillinase. This penicillinase activity tips the balance in such strains, rendering them resistant in large inocula; a zone of inhibition is usually seen around a 'high level' penicillin disc, but not around the 'low level' disc. Resistance in these organisms can be suppressed by inhibition of penicillinase activity (see HamiltonMiller et al. 1964; Sutherland \& Batchelor, 1964). Klebsiella aerogenes 83 and $K$. ozaenae 61 appear to fall into this category.

Class III consists of truly resistant organisms, of high intrinsic resistance; their penicillinase content is immaterial (though usually high). No zone of inhibition is seen around the 'high level' penicillin disc, and the penicillin is useless in the treatment of these cases, even if penicillinase activity can be suppressed. Ten strains in this series belong to this category.

The situation in regard to penicillin resistance in these bacteria offers a striking resemblance to the picture of resistance to chloramphenicol, where low levels of resistance in Escherichia coli were due to enzymic destruction of the drug, but higher levels were mediated by a genetic mechanism (Merkel \& Steers, 1953); this genetic mechanism may very well be involved with the fact that the proteinsynthesizing system, which is known to be the prime target for chloramphenicol, has been shown to be able to operate by an alternative route which is not susceptible to inhibition by chloramphenicol (Ramsey, 1958). Permeability factors have also been shown to be of paramount importance in the resistance of $E$. coli (Okamoto \& Mizuno, 1964) and Pseudomonas fluorescens (Kushner, 1955) to chloramphenicol.

The possession of a penicillinase which increases the resistance of an already inherently resistant bacterial strain can have very little, if any, evolutionary significance per se: it may be purely coincidental that inherently resistant Klebsiella strains possess penicillinase activity. Indeed, it may be recalled that both Czekalowski (1950) and Abraham (1951) have suggested that penicillinase activity may be a coincidental manifestation of the mere possession of some functionally or structurally important protein molecule; it is possible that such a molecule may be involved as an integral part of the cell-wall-membrane complex in these bacteria (see Kaufmann, 1964). Further investigations have been carried out into the nature of the permeability barrier as it exists in some of these strains, and results will be reported in a subsequent paper.

I am grateful to Beecham Research Laboratories, Ltd., to Boots Pure Drug Co. Ltd., and to Distillers Co. (Biochemicals) Ltd. for generous gifts of penicillins. Professor R. Knox and Dr J. T. Smith gave much helpful advice and criticism, and Dr D. M. MacLaren kindly provided the organisms.

Some of this work was presented in a Ph.D. thesis to London University (Hamilton-Miller, 1964).

I am grateful to the Guy's Hospital Endowments Committee for Medical Research for a grant for the support of some of this work. 


\section{REFERENCES}

Abraham, E. P. (1951). Penicillinase. In The Enzymes. Ed. by J. B. Sumner \& K. Myrbäck, vol. 1, chap. 37: New York: Academic Press.

Anderson, K. J., Kennedy, R. P., Plorde, J. J., Shulman, J. A. \& Petersdorf, R. G. (1964). Effectiveness of ampicillin against Gram-negative bacteria. J. Am. med. Ass. $187,555$.

Aycrffe, G. A. J. (1963). Ampicillin inactivation and sensitivity of coliform bacilli. J. gen. Microbiol. 30, 339.

Barber, M. \& Waterworth, P. M. (1964). Antibiotic sensitivity of Proteus species. J. clin. Path. 17, 69.

Cowan, S. T., Steel, K. J., Shaw, C. \& Duguid, J. P. (1960). A classification of the Klebsiella group. J. gen. Microbiol. 23, 601.

Czekalowskr, J. W. (1950). Penicillin inactivators of bacterial origin. J. Path. Bact. 62, 85.

Hamilton-Miller, J. M. T. (1963a). Penicillinase from Klebsiella aerogenes : a comparison with penicillinases from Gram-positive species. Biochem. J. 87, 209.

Hamiton-Muller, J. M. T. (1963b). Inducible penicillinase from Proteus morgani. Biochem. Biophys. Res. Comm. 13, 43.

HAMILton-Miluer, J. M. T. (1964). Hydrolysis of 6-aminopenicillanic acid and penicillins by bacterial penicillinases. Ph.D. thesis, University of London.

Hamilton-Miller, J. M. T. \& SMith, J. T. (1964). Inhibition of penicillinases from Grampositive and Gram-negative bacteria by substrate analogues. Nature, Lond. 201, 999.

Hamilton-Miller, J. M. T., Smith, J. T. \& Knox, R. (1964). Potentiation of penicillin activity by inhibition of penicillinase. Nature, Lond. $201,867$.

Kaufmann, W. (1964). The possible implication of a bacterial enzyme in the biochemical mode of action of penicillins on Gram-negative bacteria. Biochem. Biophys. Res. Comm. 14, 458.

KNox, R. \& Sмiтh, J. T. (1961). The nature of penicillinase resistance in staphylococci. Lancet, ii, 520.

Kushner, D. J. (1955). The basis of chloramphenicol resistance in Pseudomonas fluorescens. Arch. Biochem. Biophys. 58, 347.

LURIA, S. E. (1946). A test for penicillin sensitivity and resistance in Staphylococcus. Proc. Soc. exp. Biol. Med. 61, 46.

Merkel, J. R. \& Steers, E. (1953). Relationship between 'chloramphenicol reductase' activity and chloramphenicol resistance in Escherichia coli. J. Bact. 66, 389.

Окамото, S. \& Mizuno, D. (1964). Mechanism of chloramphenicol and tetracycline resistance in Escherichia coli. J. gen. Microbiol. 35, 125.

Percival, A., Brumfitt, W. \& de Louvors, J. (1963). The role of penicillinase in determining natural and acquired resistance of Gram-negative bacteria to penicillins. J. gen. Microbiol. 32, 77.

RAMSEY, H. H. (1958). Protein synthesis as a basis for chloramphenicol resistance in Staphylococcus aureus. Nature, Lond. 182, 602.

Rolinson, G. N. \& Stevens, S. (1961). Microbiological studies on a new broad-spectrum penicillin 'Penbritin'. Br. med. J. ii, 191.

Sabath, L. \& Finland, M. (1963). Inactivation of some semisynthetic penicillins by Gramnegative bacteria. J. Bact. 85, 314.

SмIтн, J. T. (1963). Penicillinase and ampicillin resistance in a strain of Escherichia coli. J. gen. Microbiol. 30, 299.

Smith, J. T. \& Hamilton-Miller, J. M. T. (1968). Differences between penicillinases from Gram-positive and Gram-negative bacteria. Nature, Lond. 197, 976.

SuTHERLAND, R. (1964). The nature of insensitivity of Gram-negative bacteria towards penicillins. J. gen. Microbiol. 34, 85.

Sutherland, R. \& Batchelor, F. R. (1964). Synergistic activity of penicillins against penicillinase-producing Gram-negative bacilli. Nature, Lond. 201, 868.

Trafford, J. A. P., Maclaren, D. M., Lillicrap, D. A., Barnes, R. D. S., Houston, J. C. \& KNox, R. (1962). Ampicillin: a broad spectrum penicillin. Lancet, i, 987. 